\title{
Design of Double Cranes Synchronous Control System Based on Control Network
}

\author{
Tian Hai ${ }^{1, *}$, Wang Dongsheng ${ }^{1}$, Qi Xiaojun ${ }^{2}$ and Wu Zhenkui ${ }^{1}$ \\ ${ }^{1}$ Information Engineering College, Inner Mongolia University of Science and Technology, No.7 Arding Street, Kundulun \\ District, Baotou 014010, Nei Monggol, China \\ ${ }^{2}$ Department of Automation, Baotou Iron and Steel Vocational Technical College, No.7 Arding Street, Kundulun Dis- \\ trict, Baotou 014010, Nei Monggol, China
}

\begin{abstract}
To solve the problems in the synchronous operation control of double cranes for lifting super long rail, fuzzy parameter self-tuning PID was introduced to the synchronous operation control strategy of the non rigid connection mechanism. For practical application in concrete engineering project, a fuzzy PID double crane synchronous operation control system was designed, which was implemented by PLC in control network. The network topology structure and system software and hardware configuration were introduced in detail. Structure of the fuzzy PID controller and its specific implementation process in Siemens CPU315-2DP PLC were explained also. Meanwhile, software aided design and simulation experiments for the fuzzy PID controller by making use of the simulation software MATLAB were explained. The results of simulation and practical operation effect show that, some control quality indexes of the fuzzy PID controller like overshoot, dynamic response speed and steady-state accuracy are greatly improved compared to the conventional PID. Because of the design based on control network, the system operation efficiency, real-time performance and economic benefit are also improved considerably, so it has the high value of engineering application.
\end{abstract}

Keywords: Double cranes, Fuzzy parameter self-tuning PID, Synchronous operation, Control network.

\section{INTRODUCTION}

With the rapid development of high-speed railway construction and train speed raising reconstruction, demand for $100 \mathrm{~m}$ super long high speed rail is growing. After being transported to the production line stand by the roller conveyor, the rolled 100 meter rails need to be lifted from the bench to finished product warehouse in groups by the crane for stacking and storage, then be lifted from the finished product warehouse onto the train. Because the rails are too long, two cranes are needed to operate synchronously to complete the hoisting task. To avoid long rail deformation, damage, dropping and other accidents, the corresponding main hoisting mechanisms, trolley mechanisms and the cart mechanisms of the two cranes have to maintain strict synchronous operation during the hoisting procedure, according to the control process requirements. And the system must also be steady and high efficient. Therefore, development of synchronous lifting control system with good safety and reliability, fast dynamic response and high control precision for double cranes is imminent. Synchronous hoisting control of double cranes falls into the synchronous operation control category of non rigid connection mechanisms. Synchronous operation of non rigid connection mechanisms means two or more mechanisms must work synchronously and collaboratively to complete the control task, but there isn't or aren't fixed connection or connecting shafts between or among them [1].

Based on sufficient study on previous synchronous operation control strategy of non rigid connection mechanism, the synchronous lifting control device of two cranes for 100 meter rail production line of a rail beam plant has been researched and developed. Because requirements of the control process for synchronization of the two cranes are high in terms of steady state regulating precision and dynamic response speed, a fuzzy parameter self-tuning PID controller was constructed in the design, which is combined of fuzzy control strategy and traditional PID control method. To strengthen the engineering application, a synchronous running fuzzy PID controller realized via PLC (Programmer Logic Controller) is designed by taking the control network as a carrier at the same time [2].

\section{THE CONTROL STRATEGY AND CONTROL PROCESS}

\subsection{Synchronous Operation Control Strategy}

To reduce the difficulty of the synchronous operation control, generally mechanical and electrical configuration of the two non rigid connection mechanisms should be exactly the same. The project team researched a few double cranes synchronization control system of hundred meter rail in the 
Panzhihua Iron and Steel Company, the Wuhan Iron and Steel Company and the Baotou Iron and Steel Company, and also deeply studied the same type of domestic and foreign synchronous control device of non rigid connection mechanisms. At present, the synchronous operation control strategy of non rigid connection mechanisms is divided into the following three main ways.

(1) Relay contact type synchronous operation system. The hardware design method of relay contact is used for synchronous operation device pointed out in references [3]. The system is composed of main control mechanism and controlled mechanism. The synchronous operation signal is sent to its own mechanism by the main control mechanism, at the same time, it is also sent to the controlled mechanism by dragging-type control cable to realize synchronous operation. The main shortcoming of the method is that the accumulated deviation of the open-loop synchronized running control can not be eliminated. And because all of the elements are hardware electrical elements and all of the connection is physical connection, the system response speed is slow, the control accuracy is low and the reliability is poor. This kind of synchronous operation control device is suitable for low cost and low control precision system.

(2) The open loop PLC synchronous operation control system. The PLC synchronization operation control devices involved in references [4] which are based on control network are two sets of PLC control systems with the same soft and hardware configurations respectively installed on the main control mechanism and controlled mechanism. The synchronous operation digital signals were transmitted by control network between the two sets of non rigid connection mechanisms to realize synchronous operation of the master and slave control mechanisms. Compared with the relay contact control mode, the hardware appliances and the number of electrical control circuits are greatly reduced, so the response speed and reliability of the system is greatly improved, because serial digital communication is adopted between the two mechanisms, and most of logic and interlock relationship needed for the synchronization operation can be realized by PLC programming. Shortcoming of the control mode is it's essentially a non feedback open loop control method, and the system accumulative deviation cannot be eliminated, so the control quality of synchronous operation is poor [5].

(3) PID closed loop synchronous operation system. For open loop synchronous operation system, although the system configurations of the two mechanisms are exactly the same, bias cannot be eliminated probably due to subtle differences in mechanical or electrical device of the two mechanisms, so the synchronous operation control performance is not ideal. In order to improve the synchronization performance, the closed loop control with feedback has to be used. The system pointed out in references [6] is a synchronous operation control system of two non rigid connection mechanisms driven by inverter and AC motor. When the synchronous operation control is working, the system will simultaneously put the master setpoint of motor speed to the speed given channels of both master control mechanism and controlled mechanism frequency converters. The actual displacements of the two mechanisms are measured via respec- tive sensors and the actual deviation of the displacements is calculated. Then the actual deviation is taken as a feedback value and compared to a given deviation value, and speed compensation value of the motors of the controlled mechanism is calculated by the PID controller. The control system will take the speed compensation values as an additional setpoint and put it onto the speed given channel of the inverter of the controlled mechanism. By fine-tuning the motor speed of the controlled mechanism, the deviation is corrected [7].

The drawback of this approach is that it's difficult for the traditional PID with the fixed $K_{P}, K_{I}$ and $K_{D}$ parameters to meet the control requirements for time-varying and stochastic system, which has high requirements for dynamic control performance [8]. For example, a synchronous operation control device of double cranes for 100 meter rail lifting has been used in the heavy rail production line of several rail beam plant, and the device was independently researched and developed by a famous company in the international crane transportation industry. The device still belongs to PID closed loop synchronization control device by field investigation. During synchronous running, dynamic performance of the system is poor, and it is often needed to switch to manual mode for correcting operation, sometimes accidents like rail deformation and rail dropping can even occur, and it's seriously affected the economic benefits and working efficiency.

To sum up, when the open loop control without feedback is adopted for the system, accumulated synchronous operation deviation of the two mechanisms can not be eliminated. Because of randomness and fuzziness of the controlled object, it is difficult to describe with accurate mathematical model. When simple PID control is adopted, overshoot is large, regulation time is long, synchronization performance is not ideal, and especially during the starting, braking, shifting gears or acceleration and deceleration process, therefore synchronization of the two mechanisms is poor. By the fuzzy control theory, the usual two-dimensional fuzzy controller can acquire good dynamic performance and strong robustness, so it has excellent control quality for nonlinear and uncertain variable, but the static error of the system is difficult to be eliminated and its characteristics are similar to that of PD controller [9]. From the traditional control theory, the traditional PID controller has the advantages of simple structure and stable and reliable control. In addition, its integral function can eliminate static error, but dynamic response is slow [10]. To give consideration to both of system dynamic response and static performance, an intelligent compound controller was designed. The method of fuzzy control and traditional PID control were combined to construct a fuzzy parameter self-tuning PID controller. The fuzzy PID controller is composed of two parts: conventional PID control and fuzzy reasoning parameters calibration [11].

The system is composed of main control mechanism and controlled mechanism. When the synchronous control is working, the main given value of motor speed is put on the main speed given value setting terminals of both drive inverters of the two mechanisms simultaneously. Meanwhile, the deviation $e$ and deviation change rate $e c$ in a period of time are sampled in real-time and taken as input values of 


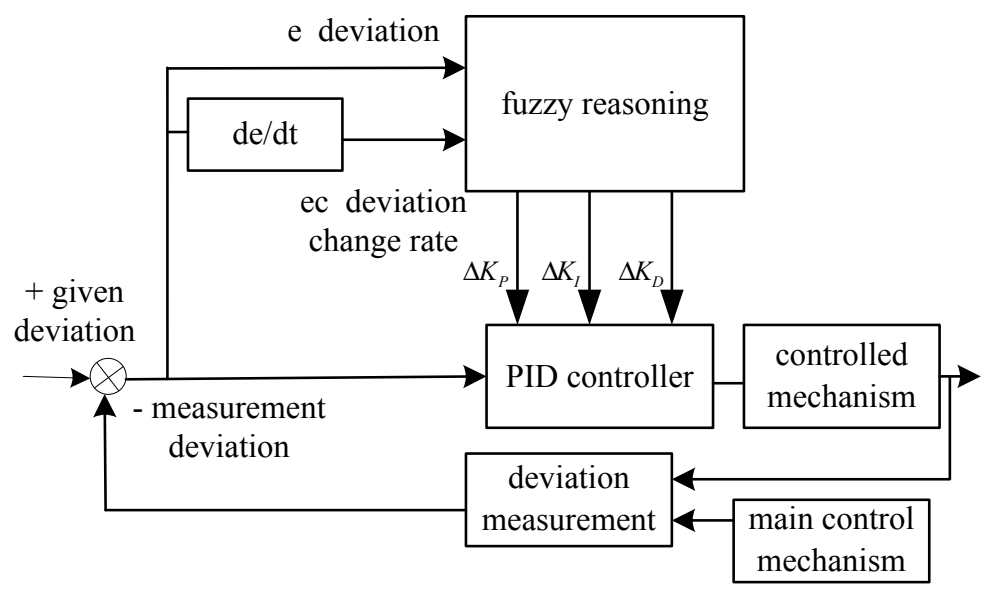

Fig. (1). The fuzzy PID controller structure.

the fuzzy PID controller, and by making use of fuzzy inference results $\Delta \mathrm{K}_{\mathrm{P}}, \Delta \mathrm{K}_{\mathrm{I}}$ and $\Delta \mathrm{K}_{\mathrm{D}}$, the three parameters of PID controller $K_{P}, K_{I}$ and $K_{D}$ are corrected in real-time. The output of the PID controller is taken as the speed compensation value of the frequency converter of the controlled mechanism, and the control system will take the speed compensation value as an additional setpoint and put it onto the additional speed given value setting terminal of the inverter of the controlled mechanism. Deviation is corrected by finetuning of motor speed of the controlled mechanism [12]. Structure of the fuzzy PID controller is shown in Fig. (1).

\subsection{System Control Process}

Because the crane sling allocated for grabbing and lifting rail is long, each crane is equipped with two independent lifting points to work together to operate a sling. That means main lifting mechanism of each crane consists of two independent hoisting mechanisms. Through synchronous control of the two non rigid connection lifting mechanisms, rising and falling of the sling are realized by the system. For each crane, two frequency converters are adopted to drive motors of each lifting mechanism independently. A frequency converter is used to drive two motors for trolley mechanism of each crane (the whole mechanism is connected rigidly). Each of the crane cart mechanism (the whole mechanism is also connected rigidly) is driven by a frequency converter, which drives four cart motors.

In order to maintain stability of the main given speed during synchronous operation of the corresponding mechanism motors of the two cranes, and give consideration to original habits of gear shifting operation of the driver, section speed control mode is used for the converters. According to the technological requirements, the main given speeds for a few motor gears are determined first, then fixed frequency corresponding to the main given speeds are set on the inverter in advance. Then during the synchronous control, different speed gears are selected by the driver and the main given speed values are applied to the drive inverters of the two mechanisms simultaneously and automatically. By means of the speed compensation value output by the fuzzy PID, the main given speed value of the controlled mecha- nism is fine-tuned to automatically eliminate the deviation. In the system each mechanism is required to have four speed grades for both forward and backward running respectively, and the speeds are set to $10 \%, 25 \%, 65 \%$ and $100 \%$ of motor rated speed in the inverters. Speed ratio of the device is 1:10.

\section{DESIGN OF CONFIGURATION OF THE TRANS- MISSION DEVICE AND CONTROL SYSTEM}

\subsection{Configuration of the Transmission Device}

(1) In order to ensure the output value of fuzzy PID controller to be executed fast and accurately, the drive inverters must have high output accuracy and dynamic response speed. For this reason, Siemens S120 series vector type frequency converter is adopted for each mechanism of the system. Speed regulation positioning accuracy of this series of frequency inverter is as high as $0.001 \mathrm{HZ}$. It has strong ability of dynamic torque regulation and strong ability of overcurrent inhibition, it can also realize four quadrant working, especially it can control static torque and output big torque at low speed [13]. In order to further improve the precision of speed positioning, control mode of the converter is chosen as closed-loop vector control with speed feedback. Therefore, an encoder is installed on each motor and motor speed is fed back in real-time to the frequency converter, and output precision of the frequency converter is improved through corresponding parameter setting on the converter, then execution precision of the transmission device is ensured.

(2) Because motors of each mechanism operate frequently and the torque often changes severely, when the model selection is made, the inverter capacity should be higher than the corresponding motor power to ensure the reliability of the operation. For example, if the motor power of a main hoisting mechanism is $45 \mathrm{KW}$, then power of the drive converter has to be chosen as $55 \mathrm{KW}$, so capacity of the inverter to bear frequent current shocks is increased significantly.

(3) In the process of mechanism deceleration and braking, regenerative energy of motors will be fed back to the DC bus of the inverter main circuit. If the DC bus voltage exceeds the rated value, the frequency converter will trip. 


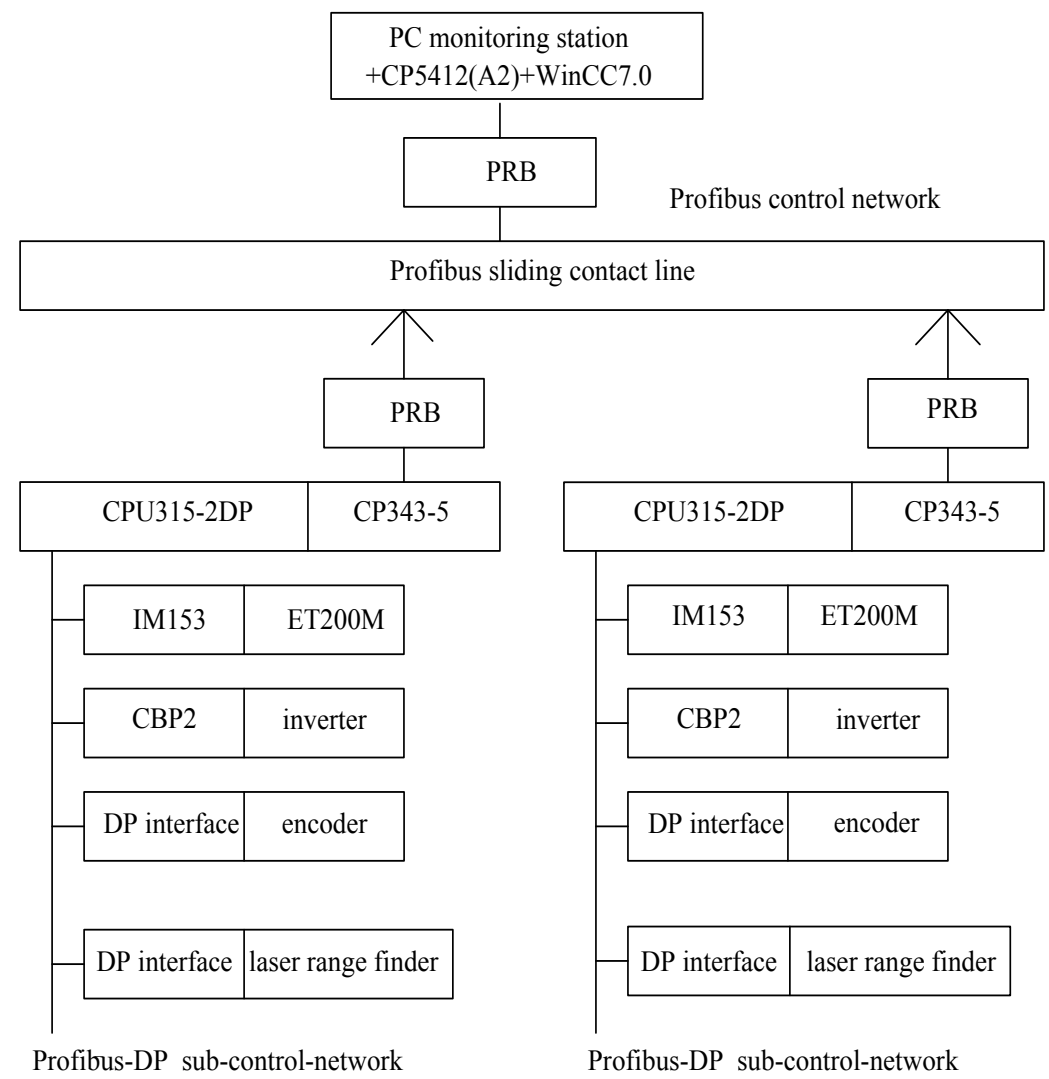

Fig. (2). Control network topology structure of the system.

The energy feedback device of common DC bus type can achieve the effect of energy saving, but for small power system the cost is too high, so in this system it is not used. Considering the performance price ratio, a brake control unit and braking resistors are installed on the frequency converter to absorb the regenerative energy of motor and improve the overload capacity of the frequency converter. Of course, this is a kind of non energy saving control mode.

\subsection{Design and Configuration of the Control Network}

Fuzzy PID double cranes synchronous operation system is realized on the platform of control network [14]. Control network is a brand new technology in which network system and control system penetrate each other, and it reflects the inevitable trend of control field developing towards networking, decentralization and digital [15]. Based on the system demand for real-time control, security and compatibility, Siemens Profibus control network system was eventually adopted. System control network topology structure is shown in Fig. (2).

Except for the same mechanical and electrical drive configuration, configuration of hardware and software of PLC system of the two cranes should be exactly the same. If it's designed like this, the master crane and the controlled crane can be set to work synchronously when it's needed, or set to work independently when it isn't needed.

Configuration of one crane is as follows: for the central processing unit (CPU), the CPU315 - 2DP model in Siemens
S7-300 PLC series is chosen, and its own Profibus-DP interface is taken as master station which forms Profibus-DP subcontrol-network. An inverter accesses to the Profibus-DP sub-network by its own Profibus-DP interface, and it will be a slave station of the sub-network. Products like laser range finder for displacement measurement and motor speed measurement encoder for the inverter closed-loop vector control with Profibus-DP interfaces are chosen, by means of their Profibus-DP interfaces the devices can access to the Profibus-DP sub-network. With the help of GSD (General Station Description) files provided by the manufacturer, this kind of device becomes a slave station of the Profibus-DP sub-network by the hardware configuration. For some other devices and signals without intelligent communication interfaces, for example, gear signal of master controller of each mechanism, limit signal of walking mechanism and electric bell signal etc, a remote $\mathrm{I} / \mathrm{O}$ slave station is set up, which is formed of ET200M and its Extended I/O module. This kind of signal is connected to the remote I/O slave station through electrical connections, and the slave station is connected to the Profibus-DP sub-control-network through the interface module IM153.

One CP343-5 communication processor is configured for the CPU315-2DP of each crane to access the Profibus control network on another higher level. The Profibus is used for communication between the two cranes and communication among the two cranes and the PC machine of the ground control station. Via the CP5412 (A2) communication card the PC is given access to the Profibus network. PLC 
variables are configured on the PC screen by means of Siemens WinCC7.0 software, and functions of the entire system can be realized, such as real-time monitoring, functions setting, data archiving, report printing, fault diagnosis and alarming [16].

When the two cranes are working synchronously, communication between the cranes or among the cranes and the ground PC monitoring station is realized by conventional towing cable, but it has poor safety and reliability. At first the wireless communication mode was considered. The current wireless communication ways suitable for PLC control network mainly include the GPRS (General Packet Radio Service), wireless radio modem and wireless Ethernet.

After study it is found that under specific conditions of this project, these ways have deficiencies and can not fully meet the requirements of the control system for high real time, safety and reliability. Through comprehensive evaluation, Siemens dedicated PRB (Power Rail Booster) device is adopted for data communication of moving parts. PRB is a special equipment used for data communication between fixed Profibus site and moving Profibus site on the sliding track. It has high reliability and its power supply mode is similar to the sliding contact line power supply of bridge crane. Mobile Profibus site is connected to the Profibus control network through PRB device. PRB is a physical transmission medium of Profibus control network, and it doesn't need to be configured and programmed.

\section{DESIGN AND IMPLEMENTATION OF THE FUZZY PID CONTROLLER}

After the master crane and controlled crane are chosen, fuzzy PID controllers of corresponding mechanisms of the two cranes will run in the master control crane CPU315-2DP PLC. Position of the corresponding mechanism of the master crane is used as following target of the synchronous running control. When corresponding mechanisms of the two cranes are working on a certain gear peed synchronously, the fixed speed of this gear is put on the main speed setting terminals of the corresponding mechanism frequency converters separately. Output of the fuzzy PID controller is used as speed compensation and applied to the additional speed setting terminal of the corresponding mechanism frequency converter of the controlled crane, and by adjusting the driven motor speed to achieve synchronous operation. By means of closed-loop speed regulation of the corresponding mechanism of the controlled crane, synchronous operation of the two cranes is realized.

Synchronous control of the main hoisting mechanisms of the two cranes is more complicated, because each crane sling has two sets of lifting mechanism of non-rigid connection, so the two cranes totally have four independent lifting mechanisms. When synchronous control of main hoisting mechanisms of the two cranes is on, position of a hoisting mechanism of the master crane is taken as the following target, and by means of respective output speed compensation of the fuzzy PID controller, the corresponding motor speeds of the other three hoisting mechanisms are fine-tuned to achieve synchronous operation. So synchronous control of the main hoisting mechanisms needs three fuzzy PID controllers to work coordinately in the CPU315-2DP PLC. Synchronous control of the cart and trolley mechanisms of the two cranes has the same principle as the main lifting mechanism, but the control is relatively simple. Each control only needs one fuzzy PID controller in the CPU315-2DP PLC of the main crane.

\subsection{Design of the Fuzzy PID Controller}

Design methods of all the fuzzy PID controllers of the main lifting mechanisms are the same, and one of them is taken as an example and introduced. Design of fuzzy PID controllers of the cart and trolley mechanisms is similar.

(1) The fuzzification of input and output variables. Fuzzy PID controller input variables $e$ and $e c$ respectively represent the deviation and the deviation change rate. The output variable $u$ contains three variables $\Delta \mathrm{K}_{\mathrm{P}}, \Delta \mathrm{K}_{\mathrm{I}}$ and $\Delta \mathrm{K}_{\mathrm{D}}$. Seven fuzzy subset $\{$ NB NM NS ZO PS PM PB $\}$ are selected for each variable $e, e c$ and $u$. Fuzzy theory domains for each variable $e, e c$ and $u$ are all set to [-6, 6] and triangle is selected as membership function curve. According to the control target and the actual operation parameters, basic theory domain of the variable $e$ is set to $[-200 \mathrm{~mm}$, $+200 \mathrm{~mm}]$; and the basic theory domain of the variation $e c$ is set to $[-40 \mathrm{~mm},+40 \mathrm{~mm}]$; the basic theory domains of output variables $\Delta K_{P}$ and $\Delta K_{I}$ are all set to $[-3,+3]$, the basic theory domain of output variable $\Delta \mathrm{K}_{\mathrm{D}}$ is set to $[-0.5,+0.5]$.

(2) Obtaining of the fuzzy rules. Fuzzy rule is the core of the fuzzy PID controller, which contains fuzzy and rich experience [17]. A set of good control rules extraction determine the strengths and weaknesses of controller performance. According to influences the $\mathrm{K}_{\mathrm{P}}, \mathrm{K}_{\mathrm{I}}$ and $\mathrm{K}_{\mathrm{D}}$ parameters have on the control system to response speed, steady state accuracy and overshoot, and by referring to practical experiences and repeated modifications, the finally fuzzy control rules are obtained, which are shown in Table $\mathbf{1}$.

(3) Clarification processing for the fuzzy output variables. After defuzzification the output of fuzzy control $\Delta K_{P}$, $\Delta K_{I}$ and $\Delta K_{D}$ are exported. Defuzzification methods mainly include gravity method, median method and the maximum membership degree method, etc [18]. Gravity method is used for defuzzification of the control system.

\subsection{PLC Realization of Fuzzy PID Controller}

Without increasing the additional cost of hardware and software, realization of the fuzzy PID controller is done by making use of the PLC system on the master crane. This design saves development costs and improves reliability of the system. In order to strengthen real-time performance of control and remedy the weak calculation ability of the PLC, first the Fuzzy Logic Toolbox of MATLAB software is used to assist design of Fuzzy reasoning of the Fuzzy PID controller, and convert the output result of Fuzzy reasoning to the lookup table that CPU315-2DP PLC can identify. Then the table is stored in the DB data block of the PLC. Software 


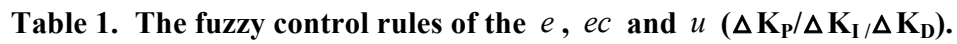

\begin{tabular}{|c|c|c|c|c|c|c|c|}
\hline$e c$ & NB & NM & NS & ZO & PS & PM & PB \\
\hline NB & $\mathrm{PB} / \mathrm{NB} / \mathrm{PS}$ & $\mathrm{PB} / \mathrm{NB} / \mathrm{NS}$ & $\mathrm{PM} / \mathrm{NM} / \mathrm{NB}$ & $\mathrm{PM} / \mathrm{NM} / \mathrm{NB}$ & $\mathrm{PS} / \mathrm{NS} / \mathrm{NB}$ & $\mathrm{ZO} / \mathrm{ZO} / \mathrm{NM}$ & $\mathrm{ZO} / \mathrm{ZO} / \mathrm{PS}$ \\
\hline NM & $\mathrm{PB} / \mathrm{NB} / \mathrm{PS}$ & $\mathrm{PB} / \mathrm{NB} / \mathrm{NS}$ & $\mathrm{PM} / \mathrm{NM} / \mathrm{NB}$ & PS/NS/NM & $\mathrm{PS} / \mathrm{NS} / \mathrm{NM}$ & $\mathrm{ZO} / \mathrm{ZO} / \mathrm{NS}$ & $\mathrm{NS} / \mathrm{ZO} / \mathrm{ZO}$ \\
\hline $\mathrm{ZO}$ & $\mathrm{PM} / \mathrm{NM} / \mathrm{ZO}$ & $\mathrm{PM} / \mathrm{NM} / \mathrm{NS}$ & $\mathrm{PS} / \mathrm{NS} / \mathrm{NS}$ & $\mathrm{ZO} / \mathrm{ZO} / \mathrm{NS}$ & NS/PS/NS & $\mathrm{NM} / \mathrm{PM} / \mathrm{NS}$ & $\mathrm{NM} / \mathrm{PM} / \mathrm{ZO}$ \\
\hline PS & $\mathrm{PS} / \mathrm{NM} / \mathrm{ZO}$ & $\mathrm{PS} / \mathrm{NS} / \mathrm{ZO}$ & $\mathrm{ZO} / \mathrm{ZO} / \mathrm{ZO}$ & $\mathrm{NS} / \mathrm{PS} / \mathrm{ZO}$ & NS/PS/ZO & $\mathrm{NM} / \mathrm{PM} / \mathrm{ZO}$ & $\mathrm{NM} / \mathrm{PB} / \mathrm{ZO}$ \\
\hline PM & $\mathrm{PS} / \mathrm{ZO} / \mathrm{PB}$ & $\mathrm{ZO} / \mathrm{ZO} / \mathrm{NS}$ & NS/PS/PS & NM/PS/PS & NM/PM/PS & $\mathrm{NM} / \mathrm{PB} / \mathrm{PS}$ & $\mathrm{NB} / \mathrm{PB} / \mathrm{PB}$ \\
\hline PB & $\mathrm{ZO} / \mathrm{ZO} / \mathrm{PB}$ & $\mathrm{ZO} / \mathrm{ZO} / \mathrm{PM}$ & NM/PS/PM & NM/PM/PM & NM/PM/PS & $\mathrm{NM} / \mathrm{PB} / \mathrm{PS}$ & $\mathrm{NB} / \mathrm{PB} / \mathrm{PB}$ \\
\hline
\end{tabular}

PID module in CPU315-2DP PLC is adopted for the conventional PID control part. when the synchronization control is on, the main crane PLC directly obtains the output value $u$ of the fuzzy inference according to the $e$ and $e c$ values and by means of the look-up table subroutine, then the $\mathrm{K}_{\mathrm{P}}, \mathrm{K}_{\mathrm{I}}$ and $\mathrm{K}_{\mathrm{D}}$ are corrected in real-time by $\Delta \mathrm{K}_{\mathrm{P}}, \Delta \mathrm{K}_{\mathrm{I}}$ and $\Delta \mathrm{K}_{\mathrm{D}}$, and directly assigned to software PID module in the PLC.

Aided design process of fuzzy reasoning of fuzzy PID controller is as follows. As the first step, two fuzzy input variable deviation $e$ and deviation change rate $e c$, and three fuzzy output variable $\Delta K_{P}, \Delta K_{I}$ and $\Delta K_{D}$ are generated in FIS editor of the fuzzy logic toolbox. The second step, fuzzy reasoning type is set as Mamdani; the And item of the fuzzy strategy is set as Min fuzzy operator, the Implication item is set to Plod; the Aggregation item is set to Sum and the defuzzification type is set to gravity center method Centroid. The third step, the membership degree function of each input and output fuzzy variable and its theory domain are input in the editor of the membership degree functions. The fourth step, the adopted fuzzy rules are input in the Rule Editor. So far the fuzzy reasoning part of the design is completed and a curved surface is obtained in the surface observer, which is the output result of the fuzzy reasoning. Although the curved surface is the fuzzy reasoning output, it cannot be read by PLC directly. So it must be converted to fuzzy reasoning query table by means of Evalfis function transform tool and copied to a DB in the CPU315-2DP PLC.

\section{ANALYSIS OF THE SIMULATION RESULTS AND ACTUAL OPERATION EFFECT}

To verify the validity of the fuzzy parameters self-tuning PID controller, the traditional PID controller and fuzzy PID controller are simulated and compared by using the Simulink software platform of the MATLAB, after the same mathematical model of the control object is established. The Ziegler-Nichols method is used to obtain the $K_{P}, K_{I}$ and $K_{D}$ fixed parameters of the conventional PID controller and the initial values of the parameters $K_{P}, K_{I}$ and $K_{D}$ of the fuzzy parameter self-tuning PID controller [19]. When the main hoisting mechanisms of the two cranes are running synchronously, the displacement deviation comparison simulation waveforms of the fuzzy parameter self-tuning PID control and traditional PID control are shown in Fig. (3).

Comparison simulation results in Fig. (3) show that the fuzzy parameter self-tuning PID control has less overshoot than the traditional PID control, and it has faster response speed, shorter regulation time and good stability, so the fuzzy parameter self-tuning PID control is apparently superior to the traditional PID control. When the time $t=7 \mathrm{~s}$, a disturbance signal is applied and both systems appear to fluctuate. The fuzzy parameter self-tuning PID control system has smaller fluctuation and shorter regulation time, and it settles down after $0.8 \mathrm{~s}$. But the traditional PID control system has bigger fluctuation and longer regulation time, and it just settles down after $1.9 \mathrm{~s}$. It is fully showed that the fuzzy parameter self-tuning PID control system has strong antiinterference ability and robustness. Main Performance indicators of the two control system are shown in Table 2 .

Before reconstruction, the traditional PID control method had been adopted for the synchronous control devices of the two cranes which had been used to lift super long rail, but it had low efficiency and high failure rate. After the synchronous operation control system of fuzzy parameters selftuning PID was put into operation, the production statistics indicate that the operation efficiency of the process has been improved by $12.8 \%$. Accidents such as rail deformation, damage and steel dropping caused by synchronizing lifting devices are reduced to an average of 2 times per month from average 36 times, so economic benefit is improved obviously.

Table 2. Comparison of performance indicators between fuzzy parameter self-tuning PID control and traditional PID.

\begin{tabular}{|c|c|c|}
\hline Control Type & Overshoot $/ \%$ & Adjusting Time $/ \mathbf{s}$ \\
\hline \hline The fuzzy PID & 8 & 2.5 \\
\hline The traditional PID & 39 & 5.7 \\
\hline
\end{tabular}




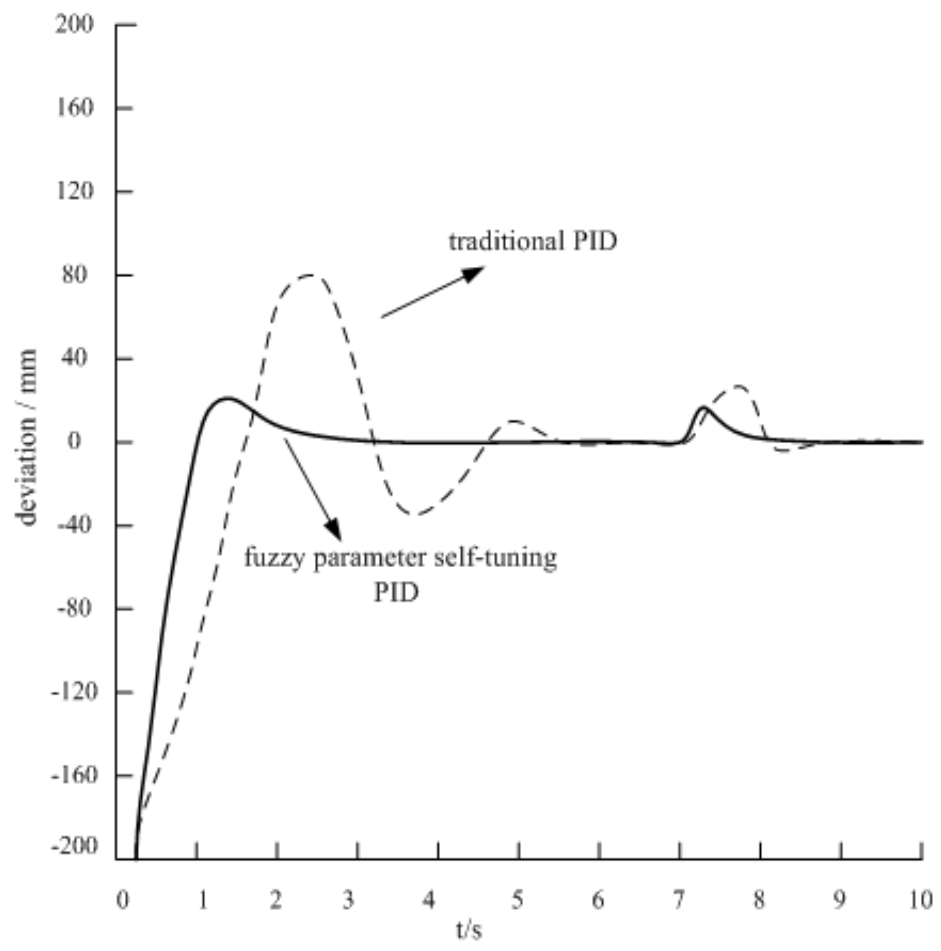

Fig. (3). Comparison simulation waveforms of the fuzzy PID control and traditional PID control.

\section{CONCLUSION}

In view of technical problems currently existing in the synchronous operation control system of double cranes both at home and abroad, the fuzzy control and traditional PID control were combined in this system and a compound fuzzy PID controller was designed. The fuzzy parameter selftuning PID controller combines the advantages of high steady state accuracy of PID adjusting and quick dynamic response of fuzzy control, and the synchronization operation quality is greatly improved. At the same time, to meet the requirement of engineering application, the fuzzy reasoning part of the compound controller was designed in MATLAB software and finally implemented through software PID module of the PLC in the Profibus control network. The control system has good real-time performance, reliability and stability, and it's convenient to operate, flexible and suitable for promotion, etc. Double cranes synchronous operation control belongs to the category of synchronous operation control of nonrigid connection mechanism, and it's a core technology of key equipment in some areas. The results of this design will have broad engineering application prospects in steel, ports, hydropower station, aerospace and other fields.

\section{CONFLICT OF INTEREST}

The author confirms that this article content has no conflict of interest.

\section{ACKNOWLEDGEMENTS}

This work was supported by the natural science fund of Inner Mongolia autonomous region, China (project number:
2013MS0921). This design was approved by the China national patent (patent number: ZL 20132 0440557.8).

\section{REFERENCES}

[1] S. Damir, B. Neven, and k. Mato, "Application of a DSP-based control system in a course in synchronous machines and excitation systems", International Journal of Electrical Engineering Education, vol. 49, no. 3, pp. 334-348, 2012.

[2] J.A. Laghari, M. Hazlie, A.B.A. Halim, and M. Hasmaini, "A fuzzy based load frequency control for distribution network connected with mini hydro power plant", Journal of Intelligent and Fuzzy Systems, vol. 26, no. 3, pp. 1301-1310, 2014.

[3] Z. Xuejun, and L. Huige, "The concurrent operations system based on electric control for bridge crane", Mechatronics, vol. 3, pp. 5356,2002

[4] T. Zhong, "How to move /load 100-meter heavy rail by two cranes synchronously", Sichuan Metallurgy, vol. 30, no. 2, pp. 6972,2008 .

[5] H. Shouxi, and Z. Dake, "Dynamic simulation on the hoisting mechanism of a crane", Journal of Chongqing Jianzhu University, vol. 25 , no. 6 , pp. $67-73,2003$.

[6] K. Hassan, and M. James, "Synchronisation of a multi-motor speed control system", Assembly Automation, vol. 33, no. 4, pp. 374-385, 2013.

[7] L. Jun and K. Shulin, "The study on multi-motor control system based on fuzzy PID control and BP neural network", Advances in Information Sciences and Service Sciences, vol. 4, no. 1, pp. 100$107,2012$.

[8] L. Xiaofeng, L. Xinhui, W. Longshan, X. Xinhua, and C. Jinshi, "Speed synchronization control of dual-motor in large crawler crane based on fuzzy PID control", Journal of Jilin University (Engineering and Technology Edition), vol. 41, no. 3, pp. 659-664, 2011.

[9] P. Danilo, "PID and intelligent controllers for optimal timing performances of industrial actuators", International Journal of Simulation, vol. 13, no. 2, pp. 65-71, 2012.

[10] S. Skoczowski, S. Domek, K. Pietrusewicz, and B. Broel-Plater, "A method for improving the robustness of PID control", IEEE Trans- 
actions on Industrial Electronics, vol. 52, no. 6, pp. 1669-1676, 2005.

[11] L. Xiaoju, and L. Jinping, "Research and simulation analysis of car following system based Fuzzy PID control", Information Technology Journal, vol. 12, no. 23, pp. 7379-7384, 2013.

[12] L. Yuanyaun, W. Fuping, Z. Higuang, Z. Zhuanya, and H. Qingxi, "Fuzzy self-tuning PID controller for pressure control in VCM", Key Engineering Materials, Manufacturing Automation Technology and System I, vol. 620, pp. 598-604, 2014.

[13] L. Haiying, L. Yuanyuan, and S. Jiancheng, "Frequency control system of mining ventilator based on fuzzy control and AHP", Electric Drive, vol. 42, no. 1, pp. 17-21, 2012.

[14] K. Alok, "A review on advanced protection, automation, control functions and future control for thermal power plant", International Journal of Automation and Control, vol. 8, no. 3, pp. 211-241, 2014.
[15] C. Lee, D. Jung, and K.W. Lee, "Design and implementation of small scale electric power management system", International Journal of Control and Automation, vol. 6, no. 3, pp. 375-382, 2013.

[16] T. Hai, C. Guimei, W. Xiaohong, and X. Yanchun, "Control network configuration stratagem and application of SIMATIC PLC", Electric Drive, vol. 40, no. 1, pp. 76-80, 2010.

[17] L. Chih-Min, and L. Hsin-Yi, "Intelligent control using the wavelet fuzzy CMAC backstepping control system for twoaxis linear piezoelectric ceramic motor drive systems", IEEE Transactions on Fuzzy Systems, vol. 22, no. 4, pp. 791-802, 2014

[18] L. Xunfei, and Z. Shoufeng, "Application of fuzzy control technology in automatic intelligent cleaner charge", Electric Drive, vol 42 , no. 12, pp. 52-55, 2012.

[19] L. Qian, L. Bin, and Z. Xuedan, "Fuzzy self-adjusting PID controller design and simulation", Control and Instruments in Chemical Industry, vol. 37, no. 3, pp. 25-28, 2010.

Received: November 26, 2014

(C) Hai et al.; Licensee Bentham Open.

This is an open access article licensed under the terms of the Creative Commons Attribution Non-Commercial License (http://creativecommons.org/licenses/by-nc/3.0/) which permits unrestricted, non-commercial use, distribution and reproduction in any medium, provided the work is properly cited. 